\title{
PROTAGONISMO JUVENIL: REFLEXÕES JURÍDICO-FILO- SÓFICAS ACERCA DA PARTICIPAÇÃO DAS JUVENTUDES NO AGIR POLÍTICO CONTEMPORÂNEO
}

YOUTH PROTAGONISM: LEGAL-PHILOSOPHICAL REFLECTIONS ON PARTICIPATION OF YOUTH IN CONTEMPORARY POLITICAL ACTION

\author{
Cristiano Lange dos Santos*
}

\section{RESUMO}

O objetivo é refletir sobre a concepção que envolve o protagonismo juvenil, a participação e o agir das juventudes no campo da política. O problema é examinar o descompasso entre os conteúdos jurídicos dispostos no Estatuto da Juventude que garantem a participação dos jovens em sua dimensão de protagonismo - e a sua efetiva aplicação no campo da política. A hipótese é que há um distanciamento entre as normas previstas no Estatuto da Juventude, que garantem os jovens como sujeitos de direitos e a sua inserção nos espaços políticos de participação, para considerá-los como protagonistas qualificados em assumir uma ação, com caráter emancipatório no campo da política. $O$ método de procedimento é monográfico, com técnicas de pesquisa bibliográfica e documental. Conclui-se que o protagonismo juvenil se limitou a exercer uma dimensão pedagógica, vinculada ao âmbito escolar, incapaz de afirmar os jovens, enquanto sujeitos de direitos, capazes de fortalecer a cidadania e politização nos processos de participação política.

Palavras-chave: Direito; juventude; participação; política.

\section{ABSTRACT}

The objective is to reflect on the conception that involves youth engagement, participation and action of youths in the field of politics. The problem is to examine the misstep between the legal system set out in the Statute for Youth that ensure the participation of young people - in their dimension of en-gagement - and their effective application in the field of politics. The hypothesis is that there is a dis-tance between the norms provided for in the Statute for Youth, which guarantee young people as sub-jects of rights and their insertion in the political spaces of participation, to consider them as protago-nists capable of assuming an action with an emancipatory character in the field of politics. The procedure method is monographic, with bibliographic and documentary research techniques. It is concluded that youth engagement was limited to exercising a pedagogical dimension, correlated to the school environment, unable to affirm young people as subjects of rights, capable of strengthening citizenship and politicization in the processes of political participation.

Keywords: Law; youth; participation; politic.

* Doutor em Direito pela Universidade de Santa Cruz do Sul. Mestre em Direitos Fundamentais pela Universidade Luterana do Brasil. Advogado. cristiano.advg@gmail.com 
INTRODUÇÃO; 1 JUVENTUDE E PROTAGONISMO: CONCEPÇÕES E SUA COMPREENSÃO; 2 DIREITOS DE JUVENTUDE E PROTAGONISMO: DISPOSITIVOS DE PARTICIPAÇÃO SOCIAL NO ORDENAMENTO JURÍDICO BRASILEIRO; 3 PROTAGONISMO JUVENIL: A PARTICIPAÇÃO JUVENIL SEM AÇÃO NEM PALAVRA; CONSIDERAÇÕES FINAIS; REFERÊNCIAS.

\section{- INTRODUÇÃO}

O objetivo deste artigo é fazer uma reflexão sobre a concepção normativa que envolve a participação, protagonismo juvenil e o agir das juventudes no campo da política.

O problema definido para o artigo é examinar o descompasso entre os conteúdos jurídicos dispostos no Estatuto da Juventude que garantem a participação dos jovens - em sua dimensão de protagonismo - e a sua efetiva aplicação no campo da política.

A aprovação da Lei n. 8.069 de 13 de julho de 1990 que dispôs, sobre o Estatuto da Criança e do Adolescente (ECA), garantiu o reconhecimento de crianças, adolescentes e jovens como passíveis de atenção por políticas públicas.

Essa dimensão progressista relaciona-se com a perspectiva da ideia do protagonismo juvenil, que remete a um conceito que vem sendo veiculado como palavra de ordem dentro de um discurso pautado pela participação social dos jovens nas últimas décadas no Brasil.

Se por um lado, o uso do termo tem se apresentado como a capacidade do jovem em situação de risco de vulnerabilidade ser protagonista no desenvolvimento do país e ser inserido nos processos de inclusão social. Por outro, o protagonismo limitou-se a exercer um papel pedagógico, sem apresentar-se como elemento delineador de afirmação das juventudes, enquanto sujeito de direitos, capazes de fortalecer a cidadania, a politização e a liberdade nos processos de participação política.

Dessa maneira, o conceito apresenta diversos modos de compreensão, e é utilizado de forma direcionada, dependendo do processo de abordagem e do contexto, em que os jovens estão inseridos, para supor a sua inclusão social e política.

Porém, é necessário ressaltar que a participação dos jovens nos processos políticos é seletiva, com base nos critérios socioeconômicos, na medida em que, a desigualdade social impõe um recorte entre as diversas categorias das juventudes, nas quais, as juventudes empobrecidas e periféricas continuam como projetos pedagógicos, enquanto a juventude mais abastada pode ser considerada sujeito de direitos.

Vale dizer que a crise de representatividade política, expressa, pelo alto índice de abstinência eleitoral; apatia política; desinteresse pelas questões coletivas; desmoralização da política e dos políticos; desconfiança em relação às instituições públicas e, a emergência dos protestos antissistema, são apenas alguns dos elementos que reduzem o significado da política, no contexto contemporâneo, especialmente para os jovens. 
Ainda assim, as juventudes encontram outros modos de se afirmar, como sujeito de direitos para além do voto e expressar seu descontentamento e sua capacidade de participação na vida política. Eles trazem novas formas de compreender a realidade com saberes e experiências inovadoras.

A hipótese que sustenta a investigação é a de que há um distanciamento entre as normas previstas no Estatuto da Juventude, que garantem os jovens como sujeitos de direitos e a sua inserção nos espaços políticos de participação, para considerá-los como protagonistas capazes de assumir uma ação, com caráter emancipatório, no campo da política.

De acordo com essa perspectiva, o artigo faz parte de uma investigação centrada, sobre a dinâmica política das juventudes ${ }^{1}$, com o fim de compreender questões, em como são inseridos, participam e influenciam os processos políticos.

Para tanto, no presente artigo, faz-se uso da técnica de pesquisa documental e bibliográfica, mediante o exame e interpretação das contribuições teóricas trazidas por Hannah Arendt sobre a importância e o significado da política na contemporaneidade. A metodologia de análise utilizada é teórica, na perspectiva interpretativo-jurídica, em que coteja, partindo dos elementos normativos encontrados na pesquisa documental, oriundos dos dispositivos do Estatuto da Juventude, com os conceitos políticos arendtianos extraídos desta pesquisa bibliográfica.

O artigo está organizado em três momentos: no primeiro, apresenta-se a conceituação, do que significa ser jovem e a construção do significado do protagonismo juvenil, desde a perspectiva escolar, até sua inserção no ordenamento jurídico; no segundo desenvolve-se o processo histórico de construção normativa dos jovens, como sujeitos de direitos e sua dimensão participativa na Emenda Constitucional 65, de 13 de julho de 2010, e no Estatuto da Juventude; no terceiro, a partir das premissas teóricas de filosofia política, contidas no pensamento de Hannah Arendt, problematizam-se os conceitos dispostos nos ordenamentos jurídicos, acerca da participação com ênfase no protagonismo.

\section{JUVENTUDE E PROTAGONISMO: CONCEPÇÕES E SUA COMPREENSÃO}

O uso do conceito de juventude é marcado pela premissa da diversidade. Nesse aspecto, diferentes perspectivas de estudo sobre a juventude partem do esforço de entendêlas, de acordo, com seu contexto histórico, analisando de que forma a estrutura social vivenciada pelos jovens possibilita que, suas singularidades ou especificidades, em que são enfrentadas no espaço-tempo sejam reveladas em sua vivência.

O conceito juventude marca também uma postura política, de entendimento do sujeito individual, como um sujeito coletivo, no processo de individuação capaz de permitir construções em contextos de possibilidades e de impossibilidades, nos quais são marcados por seu

\footnotetext{
${ }^{1}$ A juventude é um público heterogêneo e eminentemente complexo, razão pela qual é preciso compreender quais seus desejos, problemas e dilemas, a fim de se desenhar políticas públicas capazes de permitir dialogar com suas linguagens e reduzir os impactos que lhes afetam. Diante dessa questão terminológica, este artigo, sempre que possível, denominará "as juventudes", utilizando-se do plural, com o fim de reafirmar a diversidade e a multiplicidade que os jovens expressam.
} 
momento histórico e por sua origem social, como sujeito dotado de sentimentos positivos e negativos, de vulnerabilidades e potencialidades, de decisões e indecisões.

A juventude é uma construção cultural relativa no tempo e no espaço, imaginada para suprir a escassez de mão de obra adulta na Revolução Industrial.

Nesse sentido, para Feixa:

Tras la segunda guerra mundial pareció imponerse en Occidente el modelo conformista de la juventud, el ideal de la adolescencia como período libre de responsabilidades, politicamente pasivo y dócil, que generaciones de educadores habían intentado imponer. En Alemania se hablaba de generación escéptica, en Italia de gioventú bruciata, en Francia de existencialismo, para referirse a las actitudes de evasión que arrastraban las secuelas de la guerra y el desencanto. ${ }^{2}$

Nesse aspecto é possível caracterizar a juventude como pessoas em processo de desenvolvimento - de transição - da infância para adolescência, capaz de protagonizar a transformação da subjetividade individual em realidade objetiva, concreta e social.

Desse modo, o termo protagonismo tem sido utilizado como sinônimo de participação ativa, ou seja, com uma posição mais destacada e qualificada, por parte dos jovens, nos distintos processos democráticos, especialmente no âmbito educacional, a partir da década de 1990.

A expressão protagonismo, de certa forma, revela a complexidade da sua conceituação e utilização, o que tem gerado algumas discussões, acerca da sua utilização na academia, que não a aceitou vindo a problematizá-la nas legislações, sobretudo aquelas em que constaram as reformas escolares e nos movimentos do terceiro setor que a massificaram reproduzindo indiscriminadamente nas suas cartilhas sociais.

A complexidade do conceito do protagonismo juvenil permite uma interpretação ampliada que pode ser associada a outros conceitos que se aproximam: participação, responsabilidade social, identidade, autonomia e cidadania.

O uso do conceito protagonismo tem se apresentado de forma dúbia para expressar a capacidade do jovem, em ser protagonista - ator principal - ou quem combate na primeira fila, ocupando o lugar principal como personagem mais notável no desenvolvimento do país, do espaço, no qual está relacionado e, em seu próprio interesse ${ }^{3}$.

Significa dizer que, o jovem passa de uma posição passiva, para uma posição de destaque, em termos participativos vindos a se apresentar, primeiramente, no âmbito escolar e, a partir dessa experiência, passa a lhe acompanhar pelo restante da vida. Para Costa e Vieira essa prática está relacionada diretamente ao jovem e se denomina de "moderna cidadania" pois incentiva a construção dos seus desejos e anseios no campo político-social de cada jovem, de maneira individual.

\footnotetext{
${ }^{2}$ FEIXA, Carles. De jóvenes, bandas y tribus. Antropologia de la juventud. Barcelona: Editorial Ariel S.A, 1999, p 41.

${ }^{3}$ SOUZA, Regina Magalhães de. Protagonismo juvenil: o discurso da juventude sem voz. Revista Brasileira Adolescência e Conflitualidade. Volume 1, 2009, p. 02.

${ }^{4}$ COSTA, Antônio Carlos Gomes da; VIEIRA, Maria Adenil. Protagonismo juvenil: adolescência, educação e participação democrática. São Paulo, SP: FTD, 2006.
} 
Souza ${ }^{5}$ problematiza o sentido da concepção protagonismo tal como apresentada, entendendo-a como: "um exercício limitado que não contribui para a emancipação plena do jovem, como forma de expressão legítima de reivindicação de direitos, mas como uma prática mercadológica, que reforça um processo de despolitização, uma vez que propõe a "ação" individual na esfera do mercado".

Essa nova "forma de política" esconde uma concepção com fundamento liberal, que surge na onda do terceiro setor, na década de 1990, com o fim de desresponsabilizar o Poder Público na formulação, implementação e execução de políticas públicas de juventude.

Para Ferretti, Zibas e Tartuce o conceito de protagonismo juvenil apresenta diversos modos de compreensão e interpretações, dependendo das formas de abordagem e do contexto, no qual os jovens estão inseridos ${ }^{6}$.

Logo, para Ferreti, Zibas e Tartuce, o protagonismo é "reconhecidamente um conceito fluído e multifacetado, carregado de significado pedagógico e político, tornando-o um potencial catalisador de conflitos e um objeto fértil para estudos"'?.

O protagonismo juvenil, segundo Costa apresenta alguns fundamentos essenciais, cujo elemento principal se encontra no fator emancipacionista e desenvolvimentista dos jovens.

\begin{abstract}
O termo Protagonismo Juvenil, enquanto modalidade de ação é a criação de espaços e condições capazes de possibilitar aos jovens envolverem-se em atividades direcionadas à solução de problemas reais, atuando como fonte de iniciativa, liberdade e compromisso. [...] O cerne do protagonismo, portanto, é a participação ativa e construtiva do jovem na vida da escola, da comunidade ou da sociedade mais ampla. (COSTA, 2001, p.179).
\end{abstract}

O protagonismo é apresentando com base na etimologia do grego protagnistés, que se refere à protos, enquanto ator principal no teatro, ou que ocupa o papel central num acontecimento e agonistes, que significa lutador, competidor, contendor ${ }^{8}$.

Cabe destacar que a proposta inicial de protagonismo envolvia especificamente o âmbito escolar, inserindo o jovem no processo de gestão educacional, ajudando-o a construir sua autonomia, emancipação e permitir a interação em situações que exigiriam seu posicionamento individual e político.

Nesse sentido, é imperativo dizer que, no âmbito da educação, a noção de protagonismo juvenil tem sido construída desde a década de 1990, sendo até mesmo promovida pelo governo federal, como elemento importante na reforma curricular, ao propor um espaço pedagógico atraente e desafiador ao jovem, com o fim de favorecer seu progresso intelectual, social e afetivo.

\footnotetext{
5 SOUZA, op. cit., p. 05.

${ }^{6}$ FERRETTI, Celso J.; ZIBAS, Dagmar M. L.; TARTUCE, Gisela Lobo B. P. Protagonismo Juvenil na Literatura Especializada e na Reforma do Ensino Médio. Cadernos de Pesquisa, São Paulo, v. 34, n.122, maio/ago. 2004, p. 411423.

7 Ibid, p. 412.

${ }^{8}$ DE TOMMASI, Lívia. Tubarões e peixinhos: histórias de jovens protagonistas. Educ. Pesqui, São Paulo, v. 40, n. 2, p. 533-548, abr./jun., 2014.
} 
E de fato, tal elemento foi previsto nas Diretrizes Curriculares Nacionais para o Ensino Médio (DCNEM), constituindo-se como prática essencial no ensino médio que incide, direta ou indiretamente, sobre as juventudes escolares para construir a cidadania9 .

No entanto, pode-se de dizer que o projeto de protagonismo juvenil, tal como apresentado por Costa (1999), tinha um significado mais protetivo, na medida em que, abrangia o ambiente escolar, em que é um espaço controlado e, envolvia o desenvolvimento pedagógico do jovem, no qual, estava inserido, diferente do sentido de participação social, que impõe a autonomia.

Tratava-se de uma estratégia pedagógica a ser desenvolvida, em ambiente escolar, entretanto, ele foi ampliando seus horizontes ${ }^{10}$. Nesse sentido, o exercício do protagonismo, compreenderia, a princípio, o jovem como um ator social, que participa de espaços de interlocução política ou que os demanda, com vistas à transformação social, a partir da própria experiência de vida dos saberes por ele vivenciado.

Houve um processo de efetivação do discurso do protagonismo juvenil, ao longo da década de 1990, sendo reproduzido constantemente como emergente e, vindo, posteriormente, a se firmar como prática nos textos do terceiro setor, especialmente as organizações ligadas diretamente a empresas.

Segundo Souza ${ }^{11}$ :

No Brasil, a organização pioneira no uso e principal responsável pela consolidação do enunciado protagonismo juvenil foi a Fundação Odebrecht, imediatamente seguida pelo Instituto Ayrton Senna e pelo Instituto Internacional para o Desenvolvimento da Cidadania (IIDAC). Em março/abril de 1996, periódico editado pela Fundação Odebrecht trazia o artigo intitulado Protagonismo juvenil: projetos estimulam adolescentes a atuarem como agentes de ações voltadas para a comunidade (ODEBRECHT INFORMA, 1996, p. 25- 26). Os projetos destinados à juventude já haviam sido objeto do periódico, mas é bastante provável que a edição de março/abril de 1996 tenha sido a primeira em que o protagonismo juvenil foi identificado como o mote das atividades da Fundação Odebrecht. Entre os anos de 1997 e 1998, o enunciado protagonismo juvenil ainda estava se firmando como designativo de um discurso, aparecendo aqui e acolá.

A proposta consistia em desenvolver "projetos sociais" direcionados especificamente à juventude em situação de vulnerabilidade, notadamente negros, pobres e regiões urbanas periféricas com o objetivo de "inseri-los na sociedade", "capacitá-los", "capacitá-los para o trabalho e para a cidadania".

\footnotetext{
${ }^{9}$ No texto das Diretrizes Nacionais para o Ensino Médio (DCNEM), a expressão protagonismo foi expressa nos artigos 3으, 70 e 10, assim como subentendida em outros dispositivos que expressam a participação na comunidade, o exercício da autonomia, a responsabilidade, a participação do jovem, e o exercício pleno da cidadania.

${ }^{10}$ Pode ser citada a Revista Protagonismo Juvenil em Revista (ano 01, edição 01, de 2013) da Secretaria Estadual de Educação de Mato Grosso, como exemplo de ação governamental para promover o protagonismo enquanto participação pedagógica no espaço escolar. Além dessa, há inúmeros outros exemplos que estimulam o protagonismo juvenil nas mais distintas esferas e ambientes.

${ }^{11}$ SOUZA, op. cit., p. 04.
} 
Significa dizer, de outra forma, que o discurso do protagonismo foi - e tem sido - muitas vezes, utilizado como uma forma de construção de sujeitos individuais que alcançam a cidadania, por meio da prestação de serviços gratuitos à coletividade e por trabalhos voluntários, direcionados a jovens empobrecidos e periféricos. Entretanto, não se consegue efetivamente construir sujeitos autônomos e conscientes do potencial de transformação político que carregam consigo.

Observa-se, portanto, a distinção do conceito do protagonismo, marcado de acordo com a condição socioeconômica, identidade e localização geográfica, na qual o jovem está inserido, na medida em que, a experiência que se exprime é a da sua realidade social. Essa concepção encontra-se caracterizada pelo efeito pedagógico que ela impõe, sobre a dimensão protagônica dos jovens no âmbito escolar.

\section{DIREITOS DE JUVENTUDE E PROTAGONISMO: DISPOSITIVOS DE PARTICIPAÇÃO SOCIAL NO ORDENAMENTO JURÍDICO BRASILEIRO}

Destaque-se que o reconhecimento dos jovens como sujeito de direitos é o núcleo central para garantir a exigibilidade dos processos de participação social e política como fundamento legitimo para que a dimensão do protagonismo seja concretizada na prática.

Em termos normativos, é imperativo mencionar a promulgação da Constituição Federal de 1988 como um marco referencial, uma vez que, previu a mudança de paradigma da situação irregular para a teoria da proteção integral, assegurando o adolescente como sujeito de direitos e não mais como "menores" vinculados aos estigmas negativos de tutela do Estado.

O artigo 227 da Constituição Federal de 1988 alterou o sistema anterior, ao garantir uma nova abordagem sobre a criança e o adolescente. Do mesmo modo, a promulgação da Lei n. 8.069 de 13 de julho de 1990 o Estatuto da Criança e do Adolescente (ECA) superou a doutrina jurídica da situação irregular, que produziu uma visão estigmatizada da infância, aprisionando conceitos jurídicos e limitando-os a concepções de controle social, vigilância e repressão do Estado.

Para Custódio ${ }^{12}$, muito embora, o modelo normativo da situação jurídica irregular tenha sido superado, seus resquícios autoritários continuam a persistir. Basta citar o exemplo trazido pelo autor, quanto à linguagem, ao utilizar-se indiscriminadamente os termos "menor infrator" e "adolescente infrator".

Com a inclusão da teoria da proteção integral na Constituição Federal de 1988, houve um redimensionamento das estruturas estatais, na tentativa de superação das práticas assistencialistas, de modo a romper com políticas emergenciais e segmentadas à crianças e adolescentes.

Adotou-se outro paradigma, respeitador dos direitos e garantias individuais, orientando-se à proteção das crianças e adolescentes, que se refere a teoria da proteção integral para lhes garantir autonomia e liberdade.

${ }^{12}$ CUSTODIO, André Viana. Teoria da Proteção Integral: pressuposto para compreensão do Direito da Criança e do Adolescente. Revista da UNISC, v.29, 2008. 
Nessa esteira de reconhecimento normativo do (ECA), em que reafirma a capacidade jurídica de crianças, adolescentes e jovens em participar, como sujeito de direitos, dos processos de tomada de decisões que envolvam seus interesses. Do mesmo modo, prevê o direito à autonomia em correspondência simétrica com os adultos para garantir seus direitos.

A autonomia é, portanto, um elemento central na estrutura normativa do (ECA). Nesse sentido, de acordo com Reichert e Wagner ${ }^{13}$ autonomia "é a capacidade de o sujeito decidir e agir por si próprio, com o pressuposto, de que o desenvolvimento e a aquisição desta habilidade sofrem a influência do contexto, em que o jovem se desenvolve".

Gohn ${ }^{14}$ constrói sua compreensão, alicerçado a luta político-social, entendendo que a "autonomia se obtém quando se adquire a capacidade de ser um sujeito histórico, que sabe ler e reinterpretar o mundo; quando se adquire uma linguagem que possibilita ao sujeito participar de fato, compreender e se expressar por conta própria".

Importa dizer, contudo, que o grau de autonomia que os jovens podem ter depende muito de suas experiências, vivências e conhecimento sobre si, sua realidade e sua interação com o meio social.

Muito embora o (ECA) não utilize o termo "protagonismo juvenil", tal como expressa em seu texto normativo, ele se aproxima, em muito da sua compreensão, pois caracteriza a concepção da garantia de que as crianças, adolescentes e jovens, em um regime democrático são efetivamente sujeitos de direitos, capazes de participar em condições de igualdade com os adultos.

A Emenda Constitucional n. 65, de 13 de julho de 2010, consolidou a juventude como um foco de prioridade absoluta na produção de políticas públicas, ao incluir o termo "jovem" no artigo 227 da Constituição Federal representando, no aspecto do marco normativo, um avanço considerável, em termos de garantias e políticas públicas, para dispor sobre a necessidade de formulação do Estatuto da Juventude (EJ) e do Plano Nacional da Juventude (PNJ) ${ }^{15}$.

De tal modo, a inclusão da categoria "jovem" com status constitucional, assegurou a potencialidade máxima, em termos de efetividade jurídica normativa, de forma a reordenar todo o sistema de garantias com vistas a realizar e efetivar tais preceitos, de proteção e estruturação de políticas de juventude.

Logo, a teoria da proteção integral abrangeu a juventude, o que lhe garantiu receber prioridade absoluta, no que tange à formulação e implementação de políticas públicas específicas.

Em decorrência disso, a promulgação da Lei n. 12.852, de 05 de agosto de 2013, a qual se denominou Estatuto da Juventude, ao reparar o esquecimento com a categoria dos jovens,

\footnotetext{
13 REICHERT, Claudete Bonato; WAGNER, Adriana. Considerações sobre a Autonomia na contemporaneidade. Estudos e Pesquisas em Psicologia, v.7 n.3, Rio de Janeiro, dez. 2007, p. 49.

${ }^{14} \mathrm{GOHN}$, Maria da Glória. O protagonismo da sociedade civil: movimentos sociais, ONGs e redes solidárias. São Paulo: Cortez, 2008, p. 33.

${ }^{15}$ A Emenda Constitucional n. 65 de 13 de julho de 2010 foi o resultado de intensa mobilização juvenil, organizações e instituições que já trabalhavam com a juventude ao longo das últimas duas décadas para inserir os jovens como objeto de proteção constitucional. Foram realizadas diversas Audiências Públicas, debates, além de Conferências Municipais e Estaduais que culminaram, até aquele momento, na realização de três Conferências Nacionais, no ano de 2008, 2011 e 2015 todas em Brasília.
} 
também significou dispor com ênfase sobre direitos, princípios e diretrizes de políticas públicas específicas direcionadas a essa faixa etária.

O Estatuto da Juventude trouxe inúmeras diretrizes gerais para a formulação de políticas públicas voltadas ao jovem, a fim de instituir uma rede de proteção social e determinar a criação de Conselhos de Direitos sobre a temática ${ }^{16}$.

O Estatuto da Juventude é composto por 48 artigos e está dividido em dois títulos, o primeiro dispõe sobre os direitos e as políticas públicas de juventude (artigo 1ㅇ a 38) e o segundo enuncia o Sistema Nacional de Juventude (SINAJUVE) (artigos 39 a 48) ${ }^{17}$.

Muitos dos direitos assegurados representam concessões genéricas, recaindo na ineficácia da lei e sem qualquer efeito prático, isso porque o Estatuto da Juventude está ancorado no sistema programático, sem capacidade de implementação imediata dos direitos nela assegurados, o que posterga seus efeitos jurídicos e recai na inaplicabilidade dos seus preceitos.

Embora se trate de uma legislação que reconheça alguns dos "novos" direitos de juventude - que foram negligenciados até então - ela trouxe poucas inovações, acerca da exigência de formulação de políticas públicas voltadas aos jovens.

Os dispositivos que asseguram direitos, como o direito à educação (artigo 700), direito à profissionalização, ao trabalho e à renda (artigo 14), direito à diversidade e à igualdade (artigo 17), direito à saúde (artigo 19), direito à cultura (artigo 21), direito à comunicação e à liberdade de expressão (artigo 26), direito ao lazer (artigo 28), direito ao território e à mobilidade (artigo 31), direito à sustentabilidade e ao meio ambiente (artigo 34) e o direito à segurança pública e o acesso à justiça (artigo 37), tal como dispostos, são incapazes de modificar a realidade social de milhares de jovens brasileiros.

Além disso, o Estatuto da Juventude estabeleceu alguns princípios estruturantes que se apresentam como valores axiológicos e orientadores na aplicação da lei, tendo a participação, como um elemento central desse mecanismo.

Trata-se do arcabouço principiológico que estrutura o sistema normativo do Estatuto da Juventude, ao irradiar seus preceitos ao ordenamento jurídico, integrando-os aos demais direitos assegurados. A não observância dos princípios estabelecidos no artigo 20 pode comprometer o significado e o próprio reconhecimento dos direitos de juventude, razão pela qual, sua aplicação tem caráter impositivo de aplicação.

\footnotetext{
${ }^{16}$ O Estatuto da Juventude é resultado do Projeto de Lei 4.529/2004, de autoria do deputado Benjamin Maranhão (PMDB) e protocolado em 25 de novembro de 2004, na Câmara dos Deputados pela Comissão Especial de Políticas Públicas para Juventude. O projeto, no decorrer do trâmite legislativo, sofreu diversas modificações, especialmente a partir do Substitutivo apresentado pela Dep. Manuela D’Ávila (PCdoB/RS), que condensou nove projetos de lei, apresentados com temática semelhante, durante o período que transcorreu entre a elaboração e a instalação da Comissão Especial para analisar o projeto. O projeto foi objeto de diversas audiências públicas, assim como foi objeto de discussão virtual no Portal e-Democracia, da Câmara dos Deputados. Tramitou por seis anos na Câmara dos Deputados, vindo a ser aprovado em plenário no dia 23 de novembro de 2011 e encaminhado à câmara revisora, com a numeração de Projeto de Lei Complementar (PLC) 098/2011, sendo aprovado no plenário do Senado Federal em 16 de abril de 2013. É registrar que a redação final do texto aprovado é, em termos de garantias, muito inferior se comparada à proposta original, o que enfraqueceu os direitos da juventude.

${ }^{17}$ O Sinajuve foi regulamentado pelo Decreto n. 9.306 de 15 de março de 2018 e alterado mais recentemente pelo Decreto n. 10.226 de 05 de fevereiro de 2020, a fim de simplificar a adesão dos demais entes federados ao sistema, haja vista a falta de interesse dos demais entes federados em participar do sistema.
} 
Esses princípios têm eficácia plena no ordenamento jurídico e devem ser aplicados em defesa dos direitos de juventude. Além disso, é importante registrar a ressalva prevista no $§ 10$ do artigo 3o do Decreto 9.306, de 15 de março de 2018, sobre a observância dos princípios nas ações realizadas pelo governo federal.

O princípio da promoção da autonomia e emancipação, previsto no inciso I do artigo $2 \stackrel{2}{ }$, pressupõe a capacidade de permitir aos jovens construir sua identidade cultural, fazer suas próprias escolhas, práticas, como forma de independência do universo adulto. Nesse sentido, cabe ao Estado, à sociedade e à família, conjunta ou individualmente, estabelecer formas de permitir aos jovens ter novas experiências, capazes de torná-los autônomos e confiantes, preparando-Ihes para a vida adulta.

É importante ressaltar que a emancipação, neste caso, não possui o sentido jurídico previsto no direito privado (artigo 50 do Código Civil), de tornar-se capaz para os atos da vida civil antes dos 18 anos, mas objetiva garantir a independência dos jovens, em relação ao seu poder familiar.

O princípio da valorização da participação política, assegurado no inciso ll do artigo 20 do Estatuto da Juventude, tem como fundamento o reconhecimento do jovem, como sujeito de direitos, capaz de interferir no processo político-democrático. Em outras palavras, este princípio quer garantir o efetivo exercício dos direitos políticos assegurados aos jovens, para permitir sua livre manifestação e expressão nas esferas convencionais de poder (partidos, sindicatos, associações, conselhos).

Este princípio deve ser interpretado como uma forma de inserir o jovem nos espaços públicos de decisão e, ao mesmo tempo, como desconstruir o universo adultocêntrico dos espaços decisórios de poder político, para colocar a juventude, em par de igualdades, de condições com os adultos.

Já o princípio do reconhecimento do jovem como sujeito de direitos universais, geracionais e singulares, previsto no inciso IV, do artigo $2 \stackrel{\circ}{\circ}$, conecta-se com o fundamento trazido por Arendt $^{18}$ de que cada jovem é único e deve ser respeitado de acordo com suas singularidades e especificidades pelo Estado. Esse princípio está diretamente associado ao princípio da promoção do bem-estar, da experimentação e do desenvolvimento integral do jovem, garantido no inciso $\mathrm{V}$ do artigo 20 , pois ambos os princípios estão conectados diretamente à inserção da teoria da proteção integral que, mediante a Emenda Constitucional n. 65 de 13 de julho de 2010 passou a abranger a categoria juvenil, garantindo-Ihes proteção, assistência e autonomia.

Há ainda o princípio do diálogo do jovem com as demais gerações, insculpido no inciso VIII, do artigo 2으, que representa a necessidade de interação entre gerações, para troca de experiências, sucessos e fracassos, em prol da coletividade e do melhoramento das condições paras as próximas gerações vindouras. Muito embora, a tecnologia tenha ampliado a brecha geracional, estendendo ainda mais a distância entre uma geração e outra, o princípio busca orientar as ações públicas, no sentido de permitir esse diálogo intergeracional.

Assim como os princípios, as diretrizes gerais, nas quais, previstas no artigo 3을 estruturam o Estatuto da Juventude, com o objetivo de estimular a participação e a dimensão protagônica dos jovens no campo político e representativo.

${ }^{18}$ ARENDT, Hannah. A condição humana. Rio de Janeiro: Forense Universitária, 2007. 
As diretrizes gerais, com o número total de onze, em que se destacam as principais: i) desenvolver a intersetorialidade das políticas estruturais, programas e ações; ii) incentivar a ampla participação juvenil em sua formulação, implementação e avaliação; iii) ampliar as alternativas de inserção social do jovem, promovendo programas que priorizem o seu desenvolvimento integral e participação ativa nos espaços decisórios; iv) proporcionar atendimento, de acordo com suas especificidades perante os órgãos públicos e privados prestadores de serviços à população, visando ao gozo de direitos simultaneamente nos campos da saúde, educacional, político, econômico, social, cultural e ambiental.

Observa-se que a participação é um dos eixos estruturantes do Estatuto da Juventude, uma vez que, ao longo do seu texto, é possível identificar o total de dezoito dispositivos, nos quais orientam, indicam e reforçam a necessidade da participação do jovem nos processos de tomada de decisão, representatividade ou no campo da política.

Ainda assim, muito embora a participação seja um elemento estruturante do Estatuto da Juventude, torna-se necessário implementar espaços institucionais políticos no processo de tomada de decisão, para que os jovens possam agir, expressar-se e manifestar suas posições e opiniões e ao final decidir.

\section{PROTAGONISMO JUVENIL: A PARTICIPAÇÃO JUVENIL SEM AÇÃO NEM PALAVRA}

A proposta aqui é reflexionar a dimensão da participação, enquanto protagonismo juvenil assegurada pela legislação, notadamente, segundo o Estatuto da Juventude, cotejandose com os suportes teóricos de Hannah Arendt à luz das práticas políticas contemporâneas, a fim de problematizar os elementos de tornar os jovens os atores principais, ou protagonistas, passando-se de uma posição passiva para uma posição de participação ativa nos processos democráticos de tomada de decisão no espaço público.

Hannah Arendt compreende a política como cidadania ativa, um medium capaz de permitir às pessoas, entre si, contestar e modificar a realidade, com base na ação coletiva entreos-homens. É no espaço público que os homens e mulheres se distinguem dos demais e passam a participar da construção dos rumos da sua história e da coletividade.

Hannah Arendt estrutura seu pensamento político-filosófico, em torno das distinções de duas categorias: o espaço público e o espaço privado ${ }^{19}$. No espaço privado, Arendt sustenta haver a não revelação, que representa a privação de ser visto e ouvido pelos demais.

Em contrapartida, já no espaço público, Hannah Arendt reafirma a potencialidade do estar-com-os-outros, como espaço de interações, articulações e de constituição da vida política entre-os-homens, para um fim coletivo. Assim, para Arendt o espaço público se revela na aparência, em que tudo deve ser visto e ouvido ${ }^{20}$, como palco da ação, do discurso (fala) entreos-homens.

Se antes eram desconsiderados e destituídos de direitos as juventudes, a partir da Emenda Constitucional n. 65 de 13 de julho de 2010 e do Estatuto da Juventude passam a ser

\footnotetext{
${ }^{19}$ ARENDT, op. cit., p. 37 destaca que a "distinção entre uma esfera da vida privada e uma esfera da vida pública corresponde à existência das esferas da família e da política como entidades diferentes e separadas, pelo menos desde o surgimento da antiga cidade-estado".

${ }^{20}$ Ibid, p. 59.
} 
catalogados como sujeitos explícitos de direitos civis, políticos, econômicos, sociais e culturais, de modo a permitir que exerçam a condição de cidadãos. Logo, passíveis de cidadania, para exercer o "direito a ter direitos" e ser amparados e protegidos pelo Estado.

Conforme se verificou anteriormente o Estatuto da Juventude, tem como diretriz central, promover os jovens como sujeitos de direitos, passíveis de serem destinatários de políticas públicas fornecidas pelo Estado. Nesse sentido, os jovens deixam de ser tutelados, por seus pais ou representantes e passam "a ter direitos a uma prestação do Estado" assegurado, por meio da norma legal, o que lhes garante equiparação e isonomia, tal como dispõe o artigo 5o da Constituição Federal de 1988.

Os artigos 1ㅇ, 2으, 4ㅇ e 26 do Estatuto da Juventude, conectam-se com a ideia de alavancar os jovens à condição de sujeito de direitos capazes de transformar a cena política, permitindo-lhes participar das decisões e dos destinos da sua comunidade, para expressar suas opiniões e posições, ao menos em tese, em situação de igualdade.

É nesse sentido que o espaço público, para Arendt, é o espaço da aparência e da visibilidade, como espaço da experiência humana, cuja inter-relação entre-os-homens faz nascer à possibilidade do exercício político para transformar a realidade e a coletividade.

Vale dizer que a publicidade - tornar público e principalmente visível os atos dos homens - é um elemento essencial na esfera política, porque reflete a imagem do homem na esfera pública ${ }^{21}$.

O parágrafo único do artigo 40 do Estatuto da Juventude ressalta a potencialidade dos jovens, em sua inter-relação-com-os-homens, para inserir a participação juvenil de forma a incluir o jovem nos espaços públicos e comunitários, como pessoa ativa, livre, responsável e digna de ocupar uma posição central nos processos políticos e sociais.

Mais do que participar, o direito à participação política dos jovens, previsto no Estatuto da Juventude, no inciso IV, do parágrafo único, do artigo 4은 Ihes garante ter direito a voz e ao voto, assegurando, ao menos em tese, a serem colocados em condições de igualdade com os adultos no trato da coisa pública.

É nesse aspecto que se quer problematizar o protagonismo, enquanto discurso que prescreve certo modelo de participação política expresso no ordenamento jurídico, mas que não garante as condições mínimas de igualdade entre os sujeitos.

Fazer política, em síntese, significa aparecer para o mundo e para as pessoas e transformar ideias em ações concretas, capazes de modificar a realidade social. Essa é a potencialidade que a política traz, quando dois sujeitos ou mais se inter-relacionam para construir o comum - que vem do conceito de comunidade.

Se essa condição existe, os jovens não são considerados, uma vez que o dispositivo previsto no Estatuto da Juventude recai em inefetividade normativa, uma vez que as juventudes, lamentavelmente, não estão, ao menos no campo político representativo, conseguindo entoar sua voz, muito menos, serem ouvidos como sujeitos de direitos.

\footnotetext{
${ }^{21}$ A seguinte passagem demonstra a importância da aparência na esfera política. ARENDT, Hannah. A condição humana, p. 192 destaca: "Na ação e no discurso, os homens mostram quem são, revelam ativamente suas identidades pessoais e singulares, e assim apresentam-se ao mundo humano, enquanto suas identidades físicas são reveladas, sem qualquer atividade própria, na conformação singular do corpo e no som singular da voz".
} 
Nesse aspecto, questiona-se se as atividades desenvolvidas pelos jovens, com o fim de alcançar o protagonismo juvenil, de acordo com os modelos de participação dispostos no Estatuto da Juventude se apresentam como um modelo de ação política coletiva ou individual.

Para Arendt ${ }^{22}$ :

Agir significa tomar iniciativa, iniciar (como indica a palavra grega archein 'começar', 'ser o primeiro' e em alguns casos, governar) imprimir movimento a alguma coisa (que é o significado original do termo latino agere). Por constituir um initium, por serem recém chegados, e iniciadores pelo fato de serem nascidos, os homens tomam iniciativas initium ergo et esset est homo, ante quem nullus fuit (portanto o homem foi criado para que houvesse um começo, e antes dele ninguém existia).

Verifica-se, em Hannah Arendt, que a ação - enquanto uma categoria eminentemente política - é sempre uma realização coletiva. É nesse aspecto que $\operatorname{Arendt}^{23}$ destaca que, a ação só acontece no espaço, onde há convivência e relações humanas, pois "o poder passa a existir entre os homens, quando eles agem juntos e desaparece no instante em que eles se dispersam".

Esse elemento reforça a dupla dimensão da perspectiva política arendtiana, na medida em que, o "agir" estabelece o começo representando o "colocar em movimento" da ação, em outras palavras, o "start" que pode ser iniciado por uma única pessoa, enquanto a os demais processos necessitam obrigatoriamente da presença coletiva. Esse elemento reforça a ideia de que a ação política significa o estar-com-outros, com o fim de agir-em-comum.

Embora o artigo 5o do Estatuto da Juventude disponha que a interlocução da juventude com o poder público deva realizar-se por intermédio de associações, redes, movimentos e organizações civis, o Estado não apresenta uma política de estímulo à participação juvenil nos espaços representativos.

Ao contrário, há uma espécie de controle adultocêntrico sobre as práticas políticas dos jovens, especialmente, porque ignora os fenômenos juvenis antissistêmicos como os coletivos culturais, que são formas de engajamento e de ação coletiva, nos quais são protagonizados por jovens da periferia que politizam o comportamento das novas gerações e buscam afirmação de suas posições e opiniões no espaço público.

E o que dizer dos coletivos e organizações informais que surgem e se constituem, a partir das interrelações nas redes virtuais.

Do mesmo modo, inexiste uma política de incentivo aos entes federados para a criação dos conselhos de juventude, como espaço deliberativo e orientador das políticas de juventude, nos distintos entes municipais, estaduais ou distrital capazes de receber as contribuições políticas dos movimentos e coletivos juvenis informais que atuam nas periferias das cidades brasileiras.

Nesse aspecto, é possível identificar o distanciamento entre o protagonismo disposto nos ordenamentos jurídicos, notadamente no Estatuto da Juventude, que querem incentivar

\footnotetext{
${ }^{22}$ ARENDT, op. cit., p. 190.

${ }^{23}$ Ibid, p. 212.
} 
a ação individual dos jovens no processo de fazer coisas e agir, ainda que seja com fins políticos, e o conceito figurado por Hannah Arendt.

Nesse sentido implica, em última instância, na anulação da política, notadamente em relação ao jovem excluído do processo da política, por três razões: primeiro, pela ausência de espaços de participação social direcionados aos jovens; segundo, pela instrumentalização da ação, reduzida à atividade-meio com o fim de um objetivo quantificável e material e; terceiro, pela fabricação do consenso.

Isso porque o protagonismo, em certa medida, propõe o ativismo privado, de modo que o jovem pode, individualmente, promover a mudança, por meio do seu "fazer" singular, sem a necessidade da presença do outro, que requer a mobilização coletiva.

Esse "fazer", como o ato de produzir coisas, em seu benefício próprio ou coletivo, assume o caráter instrumental, próprio da lógica privada e capitalista, como um processo do fazer entre meio e fim. Esse elemento é o mais perigoso no discurso do protagonismo juvenil, na medida em que, essa "atuação", composta pela defesa de interesses pessoais e na produção do "fazer coisas", possa substituir o lugar da política.

Mas ainda assim, mesmo que a ação seja o elemento transformador da realidade na esfera individual, ela deve estar acompanhada do discurso, pois segundo Arendt, a fala é a capacidade reveladora para que o sujeito possa ganhar visibilidade no espaço público.

A ação e o discurso são os modos, pelos quais, os seres humanos se manifestam uns aos outros, não como meros objetos físicos, mas enquanto homens ${ }^{24}$. A ação com fins políticos deve vir acompanhada do discurso e, quando não acontece, perde sua capacidade reveladora entre os humanos ${ }^{25}$.

Além disso, outro elemento crucial no discurso é a possibilidade de se fabricar o consenso, o que pode ser ainda mais preocupante, uma vez que aniquila qualquer possibilidade de oposição ou transgressão, que é, na realidade, uma das principais características da juventude.

O dissenso é um pilar norteador do fundamento da política. Visto como elemento indutor do processo associativo, entre os homens, para a resolução das divergências sobre o interesse comum.

Eliminar esse elemento caracterizador das juventudes é reduzir significativamente a capacidade de transformações que as juventudes carregam consigo. E é exatamente por essa característica que os jovens são sujeitos e que demonstram à sociedade que novas experiências são possíveis, pois estão mais inclinados a mudanças, seja na esfera subjetiva, seja na esfera coletiva.

Deve ser considerado que, uma ação política despida de debate e confronto perde seu caráter de fins políticos, transformando-se em ação social sem significativo potencial de transformação da realidade.

Ainda assim, é importante destacar que, embora toda política seja ação, nem toda ação é política. Pois a ação deve estar direcionada a um fim específico, notadamente aquele

\footnotetext{
${ }^{24}$ Ibid, p. 189.

${ }^{25}$ ARENDT, Hannah. Op. cit, p. 191. Para Hannah Arendt, se assim não fosse, "em lugar de homens que agem teríamos robôs mecânicos a realizar coisas que seriam humanamente incompreensíveis. Sem o discurso a ação deixaria de ser a ação, pois não haveria ator".
} 
relacionado ao interesse público da coletividade, mas também deve estar presente a pluralidade, como condição humana da ação.

Para Arendt ${ }^{26}$ :

\begin{abstract}
A pluralidade humana, condição básica da ação e do discurso, tem o duplo aspecto de igualdade e diferença. Se não fossem iguais, os homens seriam incapazes de compreender-se entre si e aos seus ancestrais, ou de fazer planos para o futuro e prever as necessidades das gerações vindouras. Se não fossem diferentes, se cada humano não diferisse de todos os que existiram, existem ou virão a existir, os homens não precisariam do discurso ou da ação para se fazerem entender.
\end{abstract}

Esse conceito trazido por Hannah Arendt reforça o fato dos homens serem indivíduos únicos e seres distintos capazes de uma ação original, pois é no espaço público, em que as pessoas, como tais, podem se distinguir dos demais, como ator político singular ${ }^{27}$.

Arendt entende que é no convívio com outras pessoas que, a individualização do sujeito político se constitui a cada nova iniciativa de agir com fins políticos e, pode trazer consigo algo novo e inédito para o mundo.

Aqui é interessante destacar o princípio da valorização do diálogo e convívio do jovem com as demais gerações, previsto no inciso VIII, do artigo 2ㅇ do Estatuto da Juventude, que orienta para o estímulo intergeracional de troca de opiniões, posições e aprendizagens entre ambos, como forma de fortalecer o espaço democrático.

É nesse sentido que a política é tão significativa, uma vez que ela representa a própria capacidade dos jovens em transformar seus projetos individuais em realidades direcionadas à coletividade, sejam os destinatários jovens ou não. Para isso, é necessário garantir condições básicas para sua concretização.

Em primeiro lugar, é preciso exigir do Estado a implementação das políticas públicas de juventude, tal como garantido no Estatuto da Juventude, de maneira a reduzir as desigualdades sociais entre as distintas juventudes.

A redução das desigualdades sociais repercute diretamente na igualdade e no desejo de participação das juventudes, uma vez que, em regra, é improvável que o jovem da classe trabalhadora consiga acompanhar os processos políticos, para além da sua jornada de trabalho.

Em segundo lugar, deve haver uma promoção e fortalecimento da cultura com a participação dos jovens, haja vista, que o país tem uma concepção menor da participação nos espaços públicos e políticos, a fim de descontruir a máxima, de que votar e ser votado significa o máximo, em que o regime democrático assegure. Nesse aspecto, é preciso educar para a participação, construindo espaços na gestão escolar para que as crianças, adolescentes e jovens possam construir-se, enquanto sujeitos autônomos e independentes, o que pode levar à cidadãos politicamente mais participativos, conscientes e politizados.

\footnotetext{
${ }^{26}$ ARENDT, op. cit., p. 188.

27 Ibid., p. 16. Arendt entende a pluralidade como "a condição da ação humana pelo fato de sermos todos os mesmos, isto é, humanos sem que ninguém seja exatamente igual a qualquer pessoa que tenha existido, exista ou venha a existir".
} 
Percebe-se, assim, a necessidade de criação de espaços de participação social, onde o jovem possa se expressar, ao falar (discurso), mas especialmente em ser ouvido, entre os seus, e especialmente pelos adultos. Dessa maneira e, nesse aspecto, o inciso II, do artigo 60 do Estatuto da Juventude que prevê como diretriz da interlocução institucional dos jovens o incentivo à criação de conselhos de juventude, recai em um dispositivo ineficaz, sem qualquer aplicabilidade porque faculta aos demais entes da Federação e, não os obriga a sua criação.

A capacidade de comunicar-se está relacionada diretamente com a linguagem. Nessa perspectiva, a escola, como espaço de construção da sua subjetividade, tem um papel fundamental no desenvolvimento da criança, adolescente e do jovem participativo, porque mediante suas vivências e experiências, eles aprenderão como agir no campo social, onde atuarão, inter-relacionando-se com os demais, aprendendo com quem poderá fazer uma aliança ou simplesmente negociar, ou, ao contrário, contra quem deve se defender.

Esses elementos consolidam jovens como sujeitos de direitos, e delineiam trajetórias de vida que carregam a consciência da cidadania e da participação, como espaços de construção coletiva para toda a sua vida.

Por isso, o discurso do protagonismo juvenil, se implementado, na perspectiva da liberdade política, em âmbito escolar, pode estimular a participação dos jovens em outros espaços políticos ou de participação social no futuro.

Em terceiro lugar, é preciso reestruturar o papel das instituições públicas e políticas, com vistas a modificar o modelo de participação dos jovens, para reconstruir um modelo descentralizado, o qual se apoie na ampliação dos espaços de atuação dos jovens, como principais conhecedores das suas próprias necessidades, na construção das políticas de juventude ${ }^{28}$.

É preciso reconhecer seus saberes e suas experiências, uma vez que eles têm muito a ensinar sobre novos parâmetros culturais e novos comportamentos sociais. É isso que Hannah Arendt destaca no conceito da pluralidade, afinal, são sujeitos únicos e insubstituíveis.

Por esta razão, que o espaço público é tão significativo, pois, mediante ele que a ação (política) entre os humanos aparece. Diferentemente das dimensões do labor e do trabalho, que podem ser executadas no isolamento social, para a confeç̧ão do objeto, a ação materializada pelo discurso (palavra) exige ocorrer, necessariamente, no público, especialmente, entre as pessoas em situação de igualdade e liberdade.

Com base nessas compreensões, é possível entender que os limites dos dispositivos relatados no Estatuto da Juventude, sobre a participação dos jovens nos espaços políticos, não garantem a constituição de sujeitos protagonistas da política.

\footnotetext{
${ }^{28}$ Sobre a estrutura de organismos com a finalidade de promoção de políticas de juventude nos Estados brasileiros, Ávila (2014) encontrou somente dois Estados que as continham com estrutura própria e orçamento específico: Amapá (Secretaria Extraordinária de Política de Juventude) e Mato Grosso do Sul (Secretaria Extraordinária da Juventude). Dos 27 Estados da federação apresentado na pesquisa somente dois possuíam estrutura própria para formular políticas públicas de juventude. Ávila (2014) também mapeou do universo da federação, 6 Estados com organismos com mais de uma pauta conjunta com a juventude: i) Amazonas (Secretaria de Estado da Juventude, Desporto e Lazer); ii) Minas Gerais (Secretaria de Estado de Esportes e da Juventude; iii) Paraíba (Secretaria da Juventude, Esporte e Lazer); iv) Pernambuco (Secretaria da Criança e da Juventude); v) São Paulo (Secretaria de Esporte, Lazer e Juventude); vi) Tocantins (Secretaria de Estado da Juventude e dos Esportes). Em síntese, Ávila (2014, p. 225) encontrou: i) 2,8\% com estrutura própria e orçamento; ii) $6,23 \%$ que dividem a temática da juventude com outra pauta (saúde, educação, esporte); iii) 9,33\% dentro de outra secretaria; e iv) 10,37\% vinculada ao gabinete do governador. Esses dados demonstram a dimensão das políticas de juventude no Brasil.
} 
Nesse aspecto, as juventudes, embora sejam reconhecidas como sujeitos de direitos dispondo da Secão I, como exclusiva, sobre o tema do Direito à Cidadania, Participação Social e Política e, à Representação Juvenil no Estatuto da Juventude, estão destituídas da ação e do discurso (fala), como atores, esvaziando-se também o seu potencial político de transformação e reivindicação em sociedade.

Nessa perspectiva, são direitos assegurados aos jovens, no artigo 26 do Estatuto da Juventude, se expressar e se manifestar politicamente no espaço público, e estão enquadrados no conceito de ação (agir) de Hannah Arendt, com o fim político de interferir no rumo dos acontecimentos. Porém, o descompasso existente, entre a norma e a liberdade de ação política, dos jovens no espaço público revela o esvaziamento do potencial político, para converter a realidade.

Pode-se constatar, segundo os aportes filosóficos de Hannah Arendt que, no modelo de participação política, no qual, vem sendo construído no Brasil, não há espaço de liberdade suficiente, para que os jovens possam agir-entre-eles, uma vez que, foram e, tem sido deslegitimados, como sujeitos políticos capazes de transformar sua realidade.

Essa perspectiva jurídica, na qual está prevista no Estatuto da Juventude impede o agir político dos jovens, negando-lhes a sua condição humana de liberdade e autonomia, porque legitima uma distinção de sujeito de direitos a depender da sua classe social. Nega-lhe também a participação política por ampliar a distância, ao acesso a tais instrumentos de protagonismo, tornando os jovens objetos da política governamental e não sujeitos dela.

\section{- CONSIDERAÇÕES FINAIS}

Verifica-se que, o protagonismo pode ser utilizado em contextos de participação, ou, vice-versa, o que permite, em determinadas situações, ambas serem sinônimos.

Ademais, foi possível perceber que o conceito de participação, com a dimensão de protagonismo, apresenta diversos modos de compreensão, sendo utilizado, de forma direcionada, dependendo do processo de abordagem e do contexto, em que os jovens estão inseridos.

O problema definido para o artigo foi examinar o descompasso entre os conteúdos jurídicos dispostos no Estatuto da Juventude, que sugerem a participação dos jovens, em sua dimensão de protagonismo e, a sua efetiva afirmação no campo da política.

A hipótese que sustentou a investigação, de que há um distanciamento, entre os preceitos normativos assegurados no Estatuto da Juventude, que estabelecem os jovens como sujeitos de direitos e a sua implementação normativa nos espaços políticos, para considerálos, como protagonistas capazes de assumir uma ação política, com caráter emancipatório no processo político ficou comprovada.

Constatou-se, de acordo com os aportes filosóficos de Hannah Arendt, que o modelo de participação - protagonismo - das juventudes, desenhado no ordenamento jurídico, que recomendam a sua inserção no campo político, impede os jovens de agir livremente no espaço político fazendo com que esses jovens sejam submetidos a um estado de impotência e isolamento político. 
Diante disso, verifica-se que a dimensão do protagonismo juvenil limitou-se a exercer uma dimensão pedagógica, na qual, vinculada ao âmbito escolar, seja incapaz de afirmar os jovens, enquanto sujeito de direitos, por ser capazes de fortalecer a cidadania e politização nos processos de participação política.

Observou-se ainda, que as juventudes são objetos e não sujeitos nas políticas. Logo, torna-se o próprio objeto das intervenções da política, no qual, se verifica pela própria inserção de diversos dispositivos, que contemplem a participação com a dimensão de protagonismo no ordenamento jurídico.

Esses dispositivos destinados exclusivamente à participação buscam o reconhecimento do jovem, como ator político estratégico e agente permanente das transformações sociais e políticas no Brasil. Para tanto, inserir o jovem nos espaços de poder é incluir um segmento historicamente excluído dos processos de tomada de decisão, além de buscar superar o discurso socialmente reproduzido, em que o jovem é despolitizado, descompromissado e passivo, em relação à política.

As juventudes, muito embora tenham sido reconhecidas como sujeito de direitos, pela Emenda Constitucional n. 65 de 13 de julho de 2010, e pelo Estatuto da Juventude, continuam a ser compreendidas, como condição de tutela e controle dos adultos, sobre os jovens, ao contrário da autonomia e da independentização das suas ações.

Essa visão também se apresenta no campo da política, uma vez que a juventude se relaciona nesse contexto, baseada em sua situação social, em relação ao adulto produzindo expressões com a perspectiva, de quem está excluído do processo de tomada de decisões no espaço público.

Vale recordar que um dos elementos nucleares do pensamento político da filósofa Hannah Arendt é de que a política só pode ser exercida, em meio à pluralidade, respeitandose a singularidade de cada um e cada uma.

Perceber o jovem como sujeito de direitos capazes de protagonizar no campo político, não se restringe somente à inclusão de dispositivos legais, tais como se verificou, mas exige a mudança de compreensão cultural e de pensamento, de que valorizar sua expressão é fortalecer a democracia.

Apesar do reconhecimento jurídico-normativo expresso no Estatuto da Juventude, é possível se perceber quão frágeis e pontuais são as ações de materialização de políticas sociais, para a juventude brasileira, especialmente, diante do agravamento de diversas expressões da questão social, para esse segmento.

A participação com a dimensão de protagonismo, da forma como foi desenhada no Estatuto da Juventude e no ordenamento jurídico, tem pouca, senão nenhuma efetividade: primeiro porque exige a formação política desde baixo, quer dizer, incentivar a participação nos âmbitos escolares, a fim de se estimular o debate e o interesse, pelo público e coletivo e; segundo, não há espaço de ação, acompanhado de discurso (fala) aos jovens, em situação de igualdade aos adultos, o que os torna impotentes e isolados no campo da política. 


\section{REFERÊNCIAS}

ARENDT, Hannah. A condição humana. Rio de Janeiro: Forense Universitária, 2007. . O que é Política? Rio de Janeiro: Editora Bertrand, 2004.

ÁVILA, Anderson. A institucionalização dos Organismos de Juventude nos Municípios. In: Anais do Encontro de Pesquisadores e Pesquisadoras de Políticas de Juventude. p. 219-232, Brasília, 2014.

BRASIL. Parâmetros Curriculares Nacionais (Ensino Médio). Ministério da Educação. Brasília [2000]. Disponível em: http://portal.mec.gov.br/seb/arquivos/pdf/blegais.pdf Acesso em: 23 mar. 2020.

COSTA, Antônio Carlos Gomes da. A presença da Pedagogia: teoria e prática da ação sócioeducativa. 2a Ed. São Paulo: Global: Instituto Ayrton Sena, 2001.

; VIEIRA, Maria Adenil. Protagonismo juvenil: adolescência, educação e participação democrática. São Paulo, SP: FTD, 2006.

CUSTODIO, André Viana. Teoria da Proteção Integral: pressuposto para compreensão do Direito da Criança e do Adolescente. Revista da UNISC, v.29, p. 22-43, 2008. Disponível em: https://online.unisc.br/seer/index.php/direito/article/viewFile/657/454 Acesso em: 26 set. 2020.

DE TOMMASI, Lívia. Tubarões e peixinhos: histórias de jovens protagonistas. Educ. Pesqui., São Paulo, v. 40, n. 2, p. 533-548, abr./jun., 2014. Disponível em: https://www.scielo.br/pdf/ep/v40n2/aop1278.pdf Acesso em: 21 jan. 2020.

FEIXA, Carles. De jóvenes, bandas y tribus. Antropologia de la juventud. Barcelona: Editorial Ariel S.A, 1999.

FERRETTI, Celso J.; ZIBAS, Dagmar M. L.; TARTUCE, Gisela Lobo B. P. Protagonismo Juvenil na Literatura Especializada e na Reforma do Ensino Médio. Cadernos de Pesquisa, São Paulo, v. 34, n.122, maio/ago. 2004, p. 411-423.

GOHN, Maria da Glória. O protagonismo da sociedade civil: movimentos sociais, ONGs e redes solidárias. São Paulo: Cortez, 2008.

REICHERT, Claudete Bonato; WAGNER, Adriana. Considerações sobre a Autonomia na contemporaneidade. Estudos e Pesquisas em Psicologia, v.7 n.3, Rio de Janeiro, dez. 2007. Disponível em: http://pepsic.bvsalud.org/pdf/epp/v7n3/v7n3a04.pdf Acesso em: 15 mai. 2020.

SOUZA, Regina Magalhães de. Protagonismo juvenil: o discurso da juventude sem voz. Revista Brasileira Adolescência e Conflitualidade. Volume 1, 2009, p.01-28.

STAMATO, Maria Isabel Calil. Protagonismo juvenil: Uma Práxis Sócio-Histórica de formação para a Cidadania. In: MESA REDONDA DO XV ENCONTRO NACIONAL DA ASSOCIAÇÃO BRASILEIRA DE PSICOLOGIA SOCIAL, 2009. Disponível em: http://www.abrapso.org.br/siteprincipal/images/Anais_XVENABRAPSO/389.\%20protagonismo\%20juvenil.pdf Acesso em: 21 fev. 2020. 